\title{
O HÍBRIDO ENERGIA ENUNCIADO POR PROFESSORES DE FÍSICA E BIOLOGIA EM FORMACุÃO INICIAL ${ }^{1}$
}

\author{
RODRIGO DOS SANTOS CREPALDE ${ }^{1 *}$ \\ ORCID: https://orcid.org/0000-0001-7025-7010 \\ ORLANDO AGUIAR JR..$^{2 * *}$ \\ ORCID: https://orcid.org/0000-0002-3900-7627
}

RESUMO: Apoiados em Bakhtin, partimos da premissa de que, na vida social, os discursos são constituídos por diferentes vozes e por diferentes linguagens sociais e que essas vozes muitas vezes se fundem, se intercalam ou são imbricadas em enunciados híbridos. Neste trabalho, procuramos compreender o processo de construção de enunciados híbridos no desenvolvimento do conceito energia e suas implicações para o ensino e aprendizagem de ciências. Analisamos interações verbais produzidas em grupos focais conduzidos pela problematização do conceito científico e cotidiano de energia por parte de licenciandos em Física e Ciências Biológicas, bolsistas do PIBID. Nas interações produzidas, observamos a bivocalização de discursos por meio da construção de híbridos orgânicos e intencionais. A compreensão dos híbridos tem o potencial de indicar a apropriação ativa e responsiva do discurso científico, o que raramente é percebido nos processos de ensinar e aprender ciências. Por fim, a partir dos resultados da pesquisa, esboçamos algumas reflexões sobre o currículo de ciências.

Palavras-chave: Enunciados híbridos. Dialogismo. Conceitos cotidianos e científicos. Ensino de energia.

\section{THE HYBRIDENERGY ENUNCIATED BY PHYSICS AND BIOLOGY TEACHERS IN INITIAL TRAINING}

ABSTRACT:Supported by Bakhtin, we start from the premise that, in social life, discourses are made of different voices and different social languages and that these voices often merge, intersect, or are embedded, in hybrid enunciations.

\footnotetext{
${ }^{1}$ Universidade Federal do Triângulo Mineiro, Departamento de Educação em Ciências, Matemática e Tecnologias Uberaba, MG, Brasil.

${ }^{2}$ Universidade Federal de Minas Gerais, Faculdade de Educação, Belo Horizonte, MG, Brasil.

"Doutor em Educação pelo Programa de Pós-Graduação em Educação da Universidade Federal de Minas Gerais (UFMG). Professor Adjunto do Departamento de Educação em Ciências, Matemática e Tecnologias da Universidade Federal do Triângulo Mineiro (UFTM), Uberaba. E-mail:<rodrigocrepalde@gmail.com >.

"* Doutor em Educação pela Universidade Federal de Minas Gerais e pós-doutorado em Educação em Ciências na Universidade de Leeds, Inglaterra (2003-04), U-Mass Boston, EUA e UFBA (2017-18). Professor Associado da Faculdade de Educação da UFMG. E-mail:< orlando@fae.ufmg.br > .
} 
The goal of this paper is to understand the process of enunciating hybrid statements for the development of energy concept and its implications for teaching and learning sciences. We analyzed verbal interactions produced in focus groups conducted by questioning both scientific and daily concepts of "energy", by student teachers in Physics and Biological Sciences, PIBID scholarship holders. In the interactions, we observed bivocalization of discourses through the construction of both organic and intentional hybrids. Understanding hybrid enunciations has the potential to indicate active and responsive appropriation of scientific discourse, which is rarely perceived in the processes of teaching and learning sciences. Finally, from the results, we outline some reflections on the sciences curriculum.

Keywords: Hybrid utterances. Dialogism. Everyday and scientific concepts. Teaching of energy.

\section{INTRODUÇÃO}

Este artigo trata da produção de enunciados híbridos por parte de estudantes de licenciatura em física e biologia ao serem estimulados, em grupos focais, a falarem sobre o conceito de energia. Nosso interesse pelo fenômeno da hibridização de discursos decorre da necessidade dos estudantes, ao aprenderem conceitos científicos, transporem fronteiras culturais entre o conhecimento científico e o conhecimento geral da vida cotidiana.

De modo geral, o uso e a apropriação do termo bíbrido pela área da Educação são acompanhados da intencionalidade em caracterizar processos, fenômenos ou dinâmicas pautados por permanências e/ou mudanças nas quais elementos de um todo/unidade teórico-analítico não são vistos a partir de relações binárias (em termos culturais, territoriais, étnicos, de gênero, de classe, de geração, etc.). Assim, a hibridização é um recurso de análise que rompe com a ideia de discursos monolíticos e busca aprofundar a dinâmica das complexas interações entre vozes na produção de enunciados. Ao mesmo tempo, não são negadas oposições, contrastes ou contradições dos elementos constituintes da unidade construída, mas é dado destaque especial à problematização das suas fronteiras, das identidades e das suas (in) determinações.

O bibrido ou hibridismo comumente é mencionado em trabalhos que problematizam o currículo (MATOS \& PAIVA, 2007), em especial, os que abordam processo de transposição/ recontextualização de conhecimentos (LOPES, 1999, 2005; TURA, 2009) e/ou a partir de estudos multi-interculturais que tomam como referência autores como Canclini (2003, 2009); 2 McLaren (1997); Bhabha (1998); ${ }^{3}$ dentre outros. 
Por sua vez, na pesquisa em Educação e Ciências podemos encontrar trabalhos que tratam do bíbrido sob o ponto de vista da relação entre conhecimentos e culturas em contextos como o de áreas de assentamentos (CARCAIOLI, 2013); da interação entre gêneros discursivos presentes em livros didáticos de ciências (BRAGA, 2003); da interpretação de enunciados. Dentre estes, destaca-se o trabalho de Araújo (2014) que explora o conceito bakhtiniano de construção híbrida ao examinar os discursos sobre calor e fogo e sobre calor e frio produzidos por comunidades situadas (bombeiros e técnicos de refrigeração, respectivamente).

$\mathrm{Na}$ pesquisa aqui relatada, procuramos compreender o processo de construção de enunciados híbridos no desenvolvimento do conceito energia e suas implicações para o ensino e aprendizagem de ciências. O fazemos entendendo, como Vigotski, que o processo de desenvolvimento de conceitos passa pelo movimento ascendente do cotidiano ao científico, pelo movimento descendente do científico ao cotidiano e, sobretudo pela ascensão ao concreto pensado (VIGOTSKI, 2009; CREPALDE \& AGUIAR, 2013). Partimos da hipótese de que em enunciados da vida cotidiana, especialmente os que evocam a palavra energia, encontramos enunciados híbridos em que estão presentes e se interpolam/intercalam a voz da ciência escolar e a voz de outros conhecimentos que fazem parte da cultura e da vida cotidiana dos estudantes. Queremos dizer com isso que assumimos a convivência de diferentes formas de pensar e dizer sobre o mundo, mas, sobretudo, damos ênfase à interação da linguagem social (BAKHTIN, 1990, 2015) da ciência escolar e de outras linguagens da vida cotidiana. Essas interações podem criar novos enunciados que não são caracteristicamente marcadas pelo cotidiano como antes, tampouco exclusivamente pertencentes ao universo do discurso científico escolar. Segundo o autor:

O objeto principal do nosso exame, pode-se dizer, seu herói principal, é o discurso bivocal, que surge inevitavelmente sob as condições da comunicação dialógica, ou seja, nas condições da vida autêntica da palavra. (BAKHTIN, 2010, p. 211, grifo do autor).

Parafraseando Bakhtin, nosso herói principal é o processo de bivocalização de discursos e a sua materialização em enunciados híbridos no contexto das relações do ensinar e aprender ciências. A partir da apropriação do referencial bakhtiniano sobre construções híbridas, analisamos interações verbais produzidas em grupos focais conduzidos pela problematização do conceito científico e cotidiano de energia por parte de licenciandos das áreas de Física e Biologia. 
Alimentados pelo objetivo de compreender a presença e implicações educacionais de construções híbridas nos enunciados sobre energia, nos orientamos pelas seguintes questões de pesquisa:

- Como as linguagens sociais da ciência escolar e do cotidiano se manifestam, se interpolam, se intercalam e se diferenciam nos discursos de professores de Física e Biologia em formação?

- Que evidências temos da consciência que estes sujeitos têm do heterodiscurso e das diferentes significações dadas ao conceito de energia?

- Quais as implicações da dialogização de diferentes vozes sociais para os processos de ensino e aprendizagem do conceito de energia?

\section{A CONSTRUCְÃO HÍBRIDA NA TEORIA DO ROMANCE DE BAKHTIN}

Buscamos categorias teórico-analíticas, por vezes, dando nosso próprio tom, na Teoria do Romance de Bakhtin, ${ }^{4}$ formulada entre os últimos anos da década de 1920 e o final da década de 1930 (BEZERRA, 2015). Nela, o autor examina o romance a partir de sua metalinguística, fundada na concepção dialógica da linguagem para o entendimento da psique e da cultura, somada agora a uma abordagem socioideológica (MORSON \& EMERSON, 2008). A obra que abrange os trabalhos do autor nesse período, publicada pela primeira vez na Rússia em 1975, foi organizada na edição de língua portuguesa com o nome de Questões de literatura e estética. ${ }^{5}$

O heterodiscurso, na acepção da expressão diversidade de discursos, é um dos conceitos chave para a teoria do romance de Bakhtin. É na análise dos procedimentos de sua introdução no romance que Bakhtin extrai a especificidade (estilística) que caracteriza esse gênero. Em traduções anteriores, a expressão é traduzida como plurilinguismo (diversidade de linguagens) ou heteroglossia (pluralidade discursiva). ${ }^{6}$

O heterodiscurso inclui os dialetos sociais, ${ }^{7}$ os jargões, as linguagens dos gêneros, das gerações, das tendências e partidos, das autoridades, das modas passageiras, até mesmo cada dia tem sua palavra de ordem, seu vocabulário, seus acentos (BAKHTIN, 2015). Mais do que um tipo de vocabulário especial ou profissional apropriado a contextos de uso específico, cada discurso ou linguagem do heterodiscurso é um modo específico de conceitualização, compreensão e avaliação do mundo (MORSON \& EMERSON, 2008). 
O plurilinguismo [heterodiscurso] configura-se como um arranjo de diversas linguagens (línguas sociais), constitutivamente dialógicas, as quais, independentemente do princípio de seu isolamento, são pontos específicos sobre o mundo, formas de interpretação verbal, perspectivas semânticas e axiológicas. As linguagens estão em inter-relação, podendo ser confrontadas, servir de complemento entre si, oporem-se umas às outras. (FLORES et al., 2009, p. 187).

Para Bakhtin, importa menos o heterodiscurso como tal e mais o processo de dialogização das vozes sociais (FARACO, 2009; FLORES et al., 2009). Na vida real, o heterodiscurso é dialogizado de múltiplas maneiras e em diferentes graus: os discursos proferidos pelos falantes participam de mais de um sistema de valores; são discutidos e reacentuados por outros discursos; tornam-se, assim, dialogizados (MORSON \& EMERSON, 2008). Portanto, o que irá caracterizar o trabalho do autor em um romance são os procedimentos (a construção híbrida é um exemplo) que ele emprega ao dialogizar o heterodiscurso. Em outras palavras, ao bivocalizar os discursos encontrados na vida social, o romancista introduz estilisticamente na sua obra o discurso do outro na linguagem do outro.

O heterodiscurso introduzido no romance (quaisquer que sejam as formas de sua introdução) é discurso do outro na linguagem do outro, que serve à expressão refratada das intenções do autor. A palavra de semelhante discurso é uma palavra bivocal especial. Ela serve ao mesmo tempo a dois falantes e traduz simultaneamente duas diferentes intenções: a intenção direta da personagem falante e a intenção refratada do autor. Nessa palavra há duas vozes, dois sentidos e duas expressões. Ademais, essas duas vozes são correlacionadas dialogicamente, como que conhecem uma à outra (como duas réplicas de um diálogo, conhecem uma à outra e são construídas nesse conhecimento recíproco), como se conversassem uma com a outra. (BAKHTIN, 2015, p. 113, grifo do autor).

O hibridismo ou a construção híbrida, isto é, a combinação de duas linguagens sociais no interior de um único enunciado, especialmente como efeito composicional e estilístico do romance, foi objeto de discussão de Bakhtin em dois textos - "Discurso no romance" (1934-1935) e "Da pré-história do discurso romanesco" $(1940)^{8}$ (RENFREW, 2015). Neste último texto, o bíbrido estilístico ${ }^{9}$ é abordado por meio da paródia de textos antigos que forneceu a base para a criação do romance moderno (BAKHTIN, 1990).

Nascia um novo modus de trabalho criativo com a linguagem: o criador aprende a ver do lado de fora, com os olhos de outrem, do ponto de vista da possivel linguagem e estilo de outrem. Pois é justamente à luz de uma outra linguagem e estilo possiveis que um dado estilo direto é parodiado, travestizado e ridicularizado. (BAKHTIN, 1990, p. 378-379, grifo do autor). 
Nestes trabalhos, Bakhtin debruça-se sobre a discussão do romance humorístico na Inglaterra, pois considera ser esta a forma mais evidente e historicamente mais importante de introdução e organização do heterodiscurso no romance. Uma forma mais comum e antiga de representar a palavra do outro por meio de outra linguagem é a paródia. Bakhtin discute alguns enunciados extraídos do romance "Little Dorrit", de Dickens. A seguir, reproduzimos o trecho com seus comentários e com destaque para o parágrafo no qual ele pela primeira vez enuncia o conceito de construção híbrida. O trecho é longo, mas se justifica pela clareza do exemplo e da definição que se segue:

"O almoço podia de fato despertar o apetite. Pratos dos mais refinados, magnificamente preparados e magnificamente servidos, frutas selecionadas e vinhos raros; maravilhas da arte em peças de ouro e prata, porcelana e cristal; um sem-número de delícias para o paladar, o olfato e a visão. Oh, que homem admirável é esse Merdle, que homem grandioso, que homem talentoso, que homem genial, em suma, que homem rico!"

O início - uma estilização paródica do alto estilo poético, seguida de um entusiástico elogio a Merdle - é um discurso alheio dissimulado do coro dos seus admiradores (grifado). A pontuação tem a função de desmascarar a hipocrisia desse coro, mostrando o fundamento real dos elogios: os adjetivos "admirável", "grandioso", "talentoso", "genial”, podem ser substituídos por uma única palavra - "rico". Esse desmascaramento pelo autor se funde imediatamente - no âmbito da mesma oração simples - com o discurso desmascarado do outro. A entusiástica acentuação dos elogios é complexificada pela segunda acentuação irônico-indignada que predomina nas últimas palavras de desmascaramento da oração.

Estamos diante de uma típica construção bíbrida de dupla dicção ${ }^{10}$ e duplo estilo.

Chamamos de construção híbrida um enunciado que, por seus traços gramaticais (sintáticos) e composicionais, pertence a um falante, mas no qual estão de fato mesclados dois enunciados, duas maneiras discursivas, dois estilos, duas "linguagens", dois universos semânticos e axiológicos. Entre esses enunciados, estilos, linguagens e horizontes, repetimos, não há nenhum limite formal - composicional e sintático, amiúde no âmbito de uma oração simples, frequentemente a mesma palavra pertence ao mesmo tempo a duas linguagens, a dois horizontes que se cruzam numa construção híbrida e, por conseguinte, tem dois sentidos heterodiscursivos, dois acentos. (BAKHTIN, 2015, p. 84-85, itálico do autor, negrito nosso).

As construções híbridas adquirem maior visibilidade no romance humorístico no qual a fala do outro, narrada, é reinterpretada sob o acento intencional de duas linguagens e perspectivas. No romance cômico inglês é característico o tratamento dado à linguagem comum de determinado grupo social, isto é, o desmascaramento do ponto de vista e valores correntes (MORSON \& EMERSON, 2008; RENFREW, 2015). 


\section{O HÍBRIDO ORGÂNICO E O HÍBRIDO INTENCIONAL}

Prosseguindo a exposição no "Discurso no Romance", mais uma vez Bakhtin retomará o conceito de hibridismo como um dos procedimentos de criação do modelo de linguagem no romance. Aqui, pela primeira vez, aparece a distinção entre híbrido intencional e involuntário, que mais à frente esse autor chamará de bíbrido intencional ${ }^{11}$ e híbrido orgânico, respectivamente.

$\mathrm{Na}$ bibridização orgânica (hibridização propriamente dita ou não-intencional) as linguagens sociais fundem-se (obscuramente) no enunciado vivo. As consciências linguísticas, correlatas de linguagens sociais distintas, aparecem como impessoais, bem como o discurso é univocalizado. ${ }^{12}$ Aqui o discurso é univocalizado no sentido em que a multidão de vozes interiorizadas que deu origem a esse enunciado é vista como uma voz, isto é, sem suas marcas de alteridade, palavras que perderam as aspas. Assim, o híbrido orgânico, apesar de ser um híbrido de linguagens sociais, mostra-se no discurso de quem o enuncia como se fosse pertencente a uma única voz. É o caso, comumente observado do discurso profissional, ${ }^{13}$ da ciência ou da ciência escolar. Apesar disso, ele pode ser bivocalizado e o é, corriqueiramente, em diferentes esferas da criação ideológica.

Por sua vez, no híbrido intencional ${ }^{14}$ (e consciente ou interiluminação mútua das linguagens) apresentam-se duas consciências linguísticas individualizadas, correlatos de dois enunciados e não de apenas duas linguagens, isto é, são duas consciências, duas vontades, duas vozes e, portanto, dois acentos que participam do híbrido literário intencional e consciente. Nesse caso, os dois discursos não estão misturados, mas dialogicamente confrontados (BAKHTIN, 2015). Isto é, o discurso é bivocalizado; num mesmo enunciado identificamos as palavras do outro e a nossa: "[...] elas são citadas direta ou indiretamente, são aceitas incondicionalmente ou são ironizadas, parodiadas, polemizadas aberta ou veladamente, estilizadas, hibridizadas" (FARACO, 2009, p. 86).

Como deve estar claro, essas duas possibilidades são polos de um continuum, e às vezes pode ser difícil dizer se um dado discurso está presente em parte [híbrido intencional] ou apenas fortemente implícito [híbrido orgânico]. A compreensão dessas dificuldades, e dos tipos complexos de bivocalização que as produzem, é fundamental para o trabalho de compreender os romances. (MORSON \& EMERSON, 2008, p. 357).

O híbrido intencional não se opõe ao híbrido orgânico, assim como podemos encontrá-los na vida cotidiana e em outros gêneros discursivos em maior ou menor grau. O híbrido intencional tem como objetivo o esclarecimento de uma linguagem por meio da outra. 
Entretanto, o híbrido intencional da vida cotidiana não é o mesmo da hibridização intencional do romance que, nesse caso, é o resultado da representação literária da linguagem, híbrido intencional e consciente, literariamente organizado, "o híbrido literário requer um trabalho gigantesco: é inteiramente estilizado, pensado, ponderado, distanciado" (BAKHTIN, 2015. p. 165).

Bakhtin supõe que provavelmente todas as linguagens de heteroglossia foram formadas por um processo de hibridização que já não é detectável pelos seus falantes. Eles usam esses híbridos orgânicos diretamente, como discurso univocalizado. Mas os falantes produzem também híbridos intencionais ao bivocalizar os discursos disponíveis, e com isso produzem suas próprias imagens das linguagens. Os romancistas iluminam tanto os híbridos orgânicos quanto os intencionais com seus próprios híbridos intencionais. (MORSON \& EMERSON, 2008, p. 358-359, grifo nosso).

Desse modo, não encontraremos em enunciados do cotidiano híbridos intencionais tais como no romance, estilizado de ponta a ponta, mas sim, híbridos intencionais construídos a partir do processo de bivocalização: o discurso do outro na linguagem do outro. Aqui não tratamos da passagem de uma linguagem para outra como se estivéssemos mudando de um cômodo para outro, mas sim numa tentativa ativa e responsiva de correlacioná-las dialogicamente.

Portanto, há tantos híbridos intencionais quantas as possibilidades de combinação de linguagens sociais realizadas pelo sujeito que enuncia. $\mathrm{O}$ discurso da ciência pela linguagem da prosa cotidiana; o discurso cotidiano pela linguagem da ciência escolar; o discurso da ciência escolar pela linguagem dos movimentos sociais; o discurso religioso pela linguagem da ciência; o discurso filosófico ou artístico pela linguagem cotidiana, dentre outros.

\section{O DISCURSO DO OUTRO NA LINGUAGEM DO OUTRO: CONSTRUÇÃO DAS CATEGORIAS}

Em trabalho anterior, Crepalde e Aguiar (2015), tivemos a oportunidade de expor o processo de construção dos híbridos em torno do conceito de energia por parte de licenciandos do campo na área de Ciências da Vida e da Natureza. As informações obtidas destes sujeitos foram provenientes de produções escritas (narrativas), atividade avaliativa de uma disciplina, que tinha como propósito desencadear, nos professores em formação, uma reflexão e síntese sobre o que aprenderam e, assim, dar a ver as relações que estabeleciam (de reconhecimento, estranhamento, encantamento, incompreensão ou recusa) com aspectos do conceito científico de energia. Em síntese, naquele momento categorizamos grande parte dos enunciados em quatro grandes blocos: 


\section{QUADRO 1}

\begin{tabular}{|l|l|l|l|}
\hline $\begin{array}{l}\text { Linguagens sociais } \\
\text { e híbridos }\end{array}$ & \multicolumn{1}{|c|}{ Predomínio } & \multicolumn{1}{|c|}{ Bivocalização } & \multicolumn{1}{|c|}{ Híbrido } \\
\hline $\begin{array}{l}\text { Linguagem Científica } \\
\text { Escolar }\end{array}$ & Voz da ciência escolar & Não há. & $\begin{array}{l}\text { Não há (ou orgânico } \\
\text { no sentido amplo) }\end{array}$ \\
\hline Linguagem Cotidiana & Voz do cotidiano & Não há. & $\begin{array}{l}\text { Não há (ou orgânico } \\
\text { no sentido amplo) }\end{array}$ \\
\hline $\begin{array}{l}\text { Híbrido Linguagem } \\
\text { Cotidiana por meio } \\
\text { da Linguagem } \\
\text { Científica Escolar }\end{array}$ & $\begin{array}{l}\text { Voz da ciência escolar } \\
\text { e do cotidiano }\end{array}$ & $\begin{array}{l}\text { Sim, movimento do } \\
\text { discurso cotidiano } \\
\text { para o discurso } \\
\text { científico escolar }\end{array}$ & $\begin{array}{l}\text { Intencional (discurso } \\
\text { do outro na } \\
\text { linguagem do outro) }\end{array}$ \\
\hline $\begin{array}{l}\text { Híbrido Linguagem } \\
\text { Científica Escolar } \\
\text { por meio da } \\
\text { Linguagem Cotidiana }\end{array}$ & $\begin{array}{l}\text { Voz da ciência escolar } \\
\text { e do cotidiano }\end{array}$ & $\begin{array}{l}\text { Sim, movimento do } \\
\text { discurso científico } \\
\text { escolar para o } \\
\text { discurso cotidiano }\end{array}$ & $\begin{array}{l}\text { Intencional (discurso } \\
\text { do outro na } \\
\text { linguagem do outro) }\end{array}$ \\
\hline
\end{tabular}

Quando caracterizamos o enunciado de determinado sujeito pelas linguagens sociais cotidiana ou científica escolar de forma isolada queremos dizer que há predomínio de uma visão de mundo (de um discurso, de uma voz) sobre seu projeto de discurso. Como exemplos, elencamos alguns enunciados proferidos pelos professores em formação inicial do campo no contexto da pesquisa anteriormente mencionada:

A energia potencial gravitacional é regulada pela atração que o planeta exerce sobre os objetos. Estes, quando abandonado de certas alturas, ficam sujeitos a aceleração de $9,8 \mathrm{~m} / \mathrm{s}^{2}$, e esta energia potencial que o corpo tem em relação ao solo é transformada em cinética, logo que o corpo entra em movimento. Pode ser medida através da relação: $\mathrm{Ep}=\mathrm{m}$.g.h onde $\mathrm{m}$ representa a massa do objeto, $\mathrm{g}$ a força da gravidade, e h a distância do corpo em relação ao solo. (Samuel).

[...] aconteceu algo bem interessante que foi calcular a quantidade de energia gasta quando se liga o chuveiro.

[...], a energia elástica está relacionada a molas, e isso eu achei superinteressante, pois nunca imaginei que o movimento de uma mola fosse um tipo de energia. (Luciana).

O enunciado de Samuel é manifestação da voz impessoal da ciência escolar. Nota-se a ausência completa de aspas e o texto é próximo do que encontraríamos impresso em livros didáticos de ciências; portanto, podemos afirmar sem sombra de dúvidas que esse é um exemplo típico de discurso univocalizado pautado pela linguagem da ciência escolar. Por sua vez, Luciana, narra uma pequena "história" 
que vivenciou nas aulas de ciências. Por meio da linguagem cotidiana, aqui também o discurso é univocalizado, refere-se a "cenas" marcantes que vivenciou, mas não entra em detalhes de como aconteceu (o que exigiria em algum grau a mobilização da linguagem da ciência escolar).

$O$ híbrido intencional linguagem cotidiana por meio da linguagem científica escolar é o discurso que faz referência, cita, traduz, bivocaliza, às vezes entre aspas, a linguagem cotidiana a partir da linguagem científica escolar. Nesse caso, observamos um enunciado híbrido intencional; é projeto/tarefa do falante demonstrar o movimento de uma linguagem social para outra. Aqui prevalecem os sentidos e visão de mundo da ciência escolar que refratam o discurso cotidiano ao ponto de recontá-lo sob o olhar da primeira. Como exemplo,

As pessoas dizem que ocorre um desperdício de energia, porém não é isso que acontece, a energia é dissipada, no exemplo da lâmpada não tem como fazer o caminho inverso e nem aproveitar a energia térmica para transformar em luminosidade. (Cristiane). ${ }^{15}$

Cristiane expõe no seu enunciado a voz da opinião corrente, da linguagem comum, "As pessoas dizem que ocorre um desperdício de energia, [...]". A bivocalização é sobre o discurso do cotidiano, isto é, o discurso do outro (comum, corriqueiro, cotidiano) é exibido na linguagem da ciência escolar. O movimento em termos da construção híbrida aqui é da linguagem cotidiana para a científica escolar: o "desperdício de energia” é negado por meio da transformação, conservação e degradação de energia

O híbrido intencional linguagem científica escolar por meio da linguagem cotidiana é o discurso que faz referência, cita, traduz bivocalizando (às vezes entre aspas), a linguagem científica escolar a partir da linguagem cotidiana. Nesse caso, também observamos um enunciado bíbrido intencional; é projeto/tarefa do falante demonstrar o movimento de uma linguagem social para outra. Aqui prevalece a visão de mundo do sujeito, que refrata e altera o sentido do enunciado científico, incorporando a eles uma nova orientação. Como exemplo,

[...] Mas o que mais interessa contar-te e que mais entusiasmo-me é como a energia é usada - isso é impressionante e nessa aula podemos afirmar que o "desperdício" de energia é muito grande - imagine só que a energia que faz funcionar o motor de um carro, a porcentagem de aproveitamento é de apenas $15 \%$, os outros $85 \%$ não se aproveita, o que significa isso no mundo em que vivemos, onde esse veículo não é só um objeto de luxo, mas tem os seus vários usos. E ainda tantas outras coisas que gastam energia, como as grandes indústrias, mas fiquemos só nesse exemplo.

Gostaria ainda de dizer-te, há um enorme distanciamento de gasto de energia entre ricos e pobres, seja nos países de primeiro mundo em relação aos outros, seja propriamente das pessoas; ainda precisamos avançar muito para se ter um mundo melhor. (Tomás, grifo nosso). 
O processo de bivocalização deste enunciado é mais explícito: podemos notar o discurso do outro na linguagem do outro. Seu enunciado introduz a degradação de energia no seu questionamento da desigualdade social. Podemos dizer que a princípio Tomás não precisa da degradação da energia para expor sua visão de mundo em relação à desigualdade social. Por outro lado, a existência de degradação de energia é independente de conflitos distributivos e questões sociais. Entretanto, o discurso científico sobre a degradação de energia por meio de sua fala crítica da desigualdade reforça e dá mais potência a sua visão de mundo. Ela serve como uma denúncia de uma sociedade baseada em relações de consumo e desperdício por parte de alguns, contrastada com a privação e carência de uma maioria.

Com esses exemplos, acreditamos que conseguimos expor um pouco do processo de construção das nossas categorias, bem como o modo como nos apropriamos do referencial bakhtiniano já mencionado nas seções anteriores. Passaremos então à análise de uma outra situação, objeto principal do nosso texto, a produção de híbridos em uma situação de interação verbal oral entre estudantes de licenciatura em Física e em Biologia.

\section{LICENCIANDOSDOPIBIDDAÁREADECIÊNCIASDANATUREZAEODESENVOLVIMENTO DE GRUPOS FOCAIS}

A iniciação à docência tal como se realiza no projeto PIBID em escolas da educação básica contribui para a inserção dos estudantes no contexto das escolas públicas desde o início da sua formação acadêmica para que desenvolvam atividades didáticopedagógicas sob orientação de um docente da licenciatura e de um professor da escola. Assim, nos deparamos com licenciandos que já estão engajados em processos de ensinar e aprender na educação básica e já possuem uma relação diferenciada com a ciência escolar se comparados a outros estudantes da licenciatura.

Nesse sentido, a escolha de sujeitos engajados no Programa Institucional de Bolsa de Iniciação à Docência (PIBID) deve-se a três motivos principais: i) o desejo de ampliar nossas considerações e conclusões sobre o desenvolvimento do conceito energia para sujeitos imersos em contextos formativos e culturais distintos; ii) garantir um grupo ou coletivo que já convive em espaços e compartilha vivências comuns com o propósito de coletar um conjunto de dados que privilegiasse interações verbais orais; iii) assegurar sujeitos em processo de formação inicial, mas que ao mesmo tempo já possuem alguma experiência em processos de ensinar e aprender ciências. 
Buscamos auxílio na metodologia dos grupos focais, pois eles têm o potencial de evidenciarem, por meio do diálogo entre os próprios sujeitos da pesquisa, o contraste, a comparação, por vezes, os conflitos no processo de produção de sentidos. Além disso, esta metodologia privilegia a análise de processos, ao invés de resultados, tão caros para a pesquisa qualitativa (BARBOUR, 2009). De uma maneira geral, podemos considerar o grupo focal como qualquer discussão em grupo com um tema, realizada com o encorajamento das interações, planejamento e conduzidas pelo pesquisador. Nos grupos focais, o pesquisador atua como um provocador e moderador dos debates. ${ }^{16}$ O tema escolhido é objeto de pesquisa do pesquisador e de algum modo deve fazer parte da experiência pessoal de cada entrevistado. A vantagem desse procedimento sobre entrevistas individuais é a de que, com os grupos focais, abre-se uma nova possibilidade de produção de interações entre os membros do grupo e não apenas entre entrevistado e entrevistador (BARBOUR, 2009; GATTI, 2012). Além disso, nos grupos focais acentuam-se os confrontos e diferentes pontos de vista, nem sempre presentes nas entrevistas individuais.

Baubour (2009) adverte que um problema comum a várias metodologias é que o respondente opta por dizer simplesmente o que pensa que queremos ouvir. Isso pode ser agravado no uso de grupo focais, pois os sujeitos entrevistados podem ter receio da desaprovação de seus pares. Ao mesmo tempo, o contexto de interação entre os pares pode proporcionar respostas mais refletidas ou até mesmo a construção de conclusões e novos questionamentos que outro método não proporcionaria. O grupo focal favorece também a explicitação de respostas, pois os participantes devem sustentá-las no debate com outros sujeitos e perspectivas.

Os grupos focais foram desenvolvidos na Faculdade de Educação de uma Universidade Federal. O ambiente já era conhecido pelos participantes, condição importante para evitar estranhamentos ou incômodos, já que eles frequentavam aulas das licenciaturas e participavam de encontros semanais do PIBID nesse mesmo local.

Fizemos a opção de trabalharmos com grupos focais de três a cinco pessoas para que o direito à voz circulasse mais vezes entre os participantes e por avaliarmos que um grupo pequeno de entrevistados cria condições favoráveis para explicitação de posições mais pessoais.

Os estudantes, bolsistas do PIBID, com o acordo prévio entre os professores supervisores do programa, eram abordados pelo pesquisador nas salas de reunião do programa, informados da pesquisa a ser desenvolvida e recebiam o convite para participação, 
de forma voluntária, nos grupos focais. Neste texto, serão objeto de análise as interações relativas a uma das questões debatidas por dois grupos focais: um com estudantes de licenciatura em Física e outro com estudantes de licenciatura em Ciências Biológicas.

As discussões foram desenvolvidas em uma sala de aula, em torno de uma mesa, e foram registradas em formato de áudio para transcrição posterior. Além disso, o pesquisador deixou claro aos participantes que todas as ideias e opiniões seriam importantes e válidas para a discussão e que o objetivo da conversa não era chegar no certo ou errado ou em um consenso "forçado" e que qualquer contribuição no debate era importante para a pesquisa que estava sendo desenvolvida.

O objeto da discussão em grupo foi um conjunto de questões em torno do uso cotidiano e científico da palavra energia em diversas situações. Construímos o seguinte roteiro, ${ }^{17}$ que orientou a condução das discussões do grupo focal:

i) É possível armazenar energia? Explique.

ii) Diz-se que uma máquina ineficiente "desperdiça energia". Isso significa realmente que a energia é perdida? Explique.

iii) Em diversas situações do nosso cotidiano compartilhamos a ideia de que "a prática de exercícios físicos é importante para uma vida saudável". Comente esse enunciado do ponto de vista da energia.

iv) Como você vê as questões de energia na sociedade brasileira, de modo geral?

v) Há outras situações e ideias diferentes, das discutidas até aqui, em que podemos empregar a palavra energia?

vi) Para você, o que é energia?

O roteiro foi aplicado com flexibilidade e abertura, não necessariamente obedecendo à ordem prévia das questões, de maneira a não interromper o fluxo da comunicação sobre um determinado tema e com o cuidado de não artificializar e empobrecer as interações como num interrogatório ou jogo de perguntas e respostas.

Em todos os grupos focais dedicamos certo tempo para conversas preparatórias e de finalização de grupo. As conversas preparatórias tinham como propósito quebrar o gelo entre o pesquisador e os entrevistados e, na medida do possível, estabelecer um ambiente de confiança mútua para favorecer interações mais espontâneas entre os participantes e o pesquisador. Isso ocorreu 
por meio das apresentações de cada sujeito, pelos comentários sobre a trajetória acadêmica desenvolvida até aquele momento (tantos dos entrevistados como do pesquisador), pela discussão sobre as potencialidades e desafios da formação de professores, dentre outros. Por outro lado, as conversas de finalização do grupo, além de serem dedicadas ao agradecimento pela participação voluntária na pesquisa, foram motivadas pelo grande interesse dos sujeitos entrevistados no tema da pesquisa. Mais especificamente, eles sentiram a necessidade de continuar o grupo para perguntar ao pesquisador sobre como trabalhar em sala de aula as energias relativas à ciência e ao cotidiano, de que modo conectaríamos os aspectos do conceito científico de energia (transferência, transformação, conservação e degradação) e manifestar questionamentos em relação à formação excessivamente disciplinar de cada uma das suas licenciaturas. ${ }^{18}$

Antes de prosseguirmos, se faz necessário mais um esclarecimento sobre o modo como construímos nossa exposição das informações provenientes dos grupos focais: transcrevemos as interações dos episódios com fontes menores e recuo em relação ao texto principal; interrompemos o fluxo da comunicação quando julgamos ser necessário explicitar as intenções do pesquisador, assim como destacar e inserir a análise do discurso dos sujeitos. Por fim, quando da omissão de algumas falas, por avaliarmos repetitivas e já contempladas em outras interações, sinalizamos os cortes por reticências entre chaves ([...]).

As informações advindas dos grupos focais são transcritas e divididas em subseções a seguir.

\section{GRUPO FOCAL 1: A TROCA E A ENERGIA}

Este grupo foi constituído por três participantes: um estudante do $5^{\circ}$ período e os outros dois do último $\left(8^{\circ}\right)$ período do curso de licenciatura em Física. O tempo de duração total do grupo focal foi de aproximadamente 1 (uma) hora e 20 (vinte) minutos: sendo que cerca de 58 (cinquenta e oito) minutos foram centrados nas questões do roteiro e o restante em conversas preparatórias e de finalização do grupo.

Para fins da exposição neste texto, analisaremos a questão da "energia e a prática de exercícios", principal condutora das nossas reflexões sobre os enunciados híbridos e o processo de bivocalização, que ocorreu quando já eram decorridos cerca de 35 minutos de diálogo em grupo:

Pesquisador: Mas vamos mudar a prosa um pouquinho aqui, só falar uma frase aqui pra ver se a gente puxa um assunto. É muito comum a gente ouvir 
no cotidiano que "a prática de exercícios físicos é importante para uma vida saudável”, pensando energia, nesse caso, fazer exercício físico, praticar exercício físico, é importante pra ter uma vida saudável. Como a gente pode pensar isso do ponto de vista da energia, por exemplo?

Lucas: Exercícios físicos você tem um desgaste, você tem um gasto dessa energia pra praticar os exercícios, mas esse gasto de energia te traria benefícios, melhor funcionamento do organismo, [inaudível, 2"].

Ricardo: É pensando em energia né, você vai fazer atividade física, você vai colocar todo o seu corpo em movimento, teoricamente. Então, assim, todo mundo vai trabalhar né, e aí você vai aumentar sua circulação, você vai alimentar mais, você vai, você vai, aí já foge da física né, mas aí você vai gerar também algumas substâncias que...

Juliano: Você tem um repositor energético, repõe essa energia.

Ricardo: Também, mas aí você vai gerar umas substâncias, seu cérebro vai entender que, tipo assim, é um sinal pro seu cérebro que vai tipo tratar, que vai te dar um bem-estar né. Mas assim, voltando pra física eu acho que como você vai ter um desgaste físico, você vai alimentar mais, eu acho que você vai ter uma troca né. E essa troca te traz a sensação do bem-estar, você vai correr - vamos imaginar corrida - você vai correr, aí cê vai esquentar demais, transpirar...

A questão inicial é introduzida de um modo particular: intencionalmente, o pesquisador quer deixar claro que o tema da conversa, do grupo focal, é a "energia, no sentido mais amplo que vocês podem imaginar". Ao introduzir essa questão desse modo e sem delimitar os contextos de uso do conceito de energia, o pesquisador fornece condições favoráveis para que nossos sujeitos manifestem enunciados para além da esfera científica escolar.

O pesquisador, intencionalmente, introduz a fala corriqueira, "a prática de exercícios físicos é importante para uma vida saudável", que favorece significações da palavra energia em torno da ideia de atividade (física) humana e das alterações metabólicas e fisiológicas dela decorrentes, assim como uma sensação de bem-estar, harmonia ou equilíbrio. A escolha da pergunta já carrega uma posição (do pesquisador) que pretende conduzir os sujeitos em uma direção, ou seja, a ideia de energia associada a prática de exercícios condensa forçosamente sentidos do cotidiano e da ciência escolar, portanto, propícios à produção de híbridos.

Há um consenso de que a energia é componente necessário para realização de atividades físicas. Para Lucas e Ricardo o "gasto" energético seria compensado pelo "melhor funcionamento do organismo", ou, como diz Ricardo, "todo mundo [partes do organismo] vai trabalhar". Juliano introduz a ideia do "repositor energético", sugerida ao final do enunciado de Ricardo, a qual 
poderia abrir outro caminho discursivo da energia na direção da sua substancialização, mas ela é incorporada como acessória no diálogo que é conduzido por Ricardo. Este último explicita um movimento de ida e vinda sobre a fronteira discursiva da física (escolar): "aí foge da física né" e "voltando para a física", respectivamente.

Por enquanto, podemos dizer que a marcação de fronteira da "física" (ciência escolar) pode tanto delimitar outra área das ciências, provavelmente a biologia, como pode referir-se a uma concepção cotidiana. No entanto, examinando os enunciados, a "física", nesse caso, parece referir-se a processos mecânicos do corpo humano; assim, estamos falando de uma "física" mais restrita, delimitada disciplinarmente pelo processo de escolarização.

Portanto, podemos perceber nos enunciados anteriores uma combinação de linguagens sociais para dar sentido à relação de duas ideias fomentadas pela pergunta inicial do pesquisador. Do ponto de vista do híbrido, estamos mais próximos de um processo de construção de enunciado mais orgânico do que intencional.

Quando os sujeitos enunciam que a relação entre energia e exercícios físicos se dá por um processo de "troca" em termos de custobenefício (gasto de energia é compensado pelo melhor funcionamento do organismo), visão de mundo fortemente marcada pelo cotidiano, eles só podem fazê-lo mobilizando híbridos, isto é, enunciar dentro de um mesmo enunciado mais de uma linguagem social.

$\mathrm{Na}$ sequência da interação, o pesquisador pressiona por centralizar sentidos em torno de uma possível contradição:

Pesquisador: Mas a sua energia aumenta ou diminui?

Ricardo: A sua energia, eu acredito que diminui. A sua energia. Porque você vai estar perdendo, você está transpirando né, tá perdendo em forma de calor, você vai tá pegando seus nutrientes e queimando. E aí, beleza, aí você fez essa troca de energia pro meio, você liberou energia pro meio, só que quando você chegar na sua casa e tomar um banho, aí cê vai pegar energia do meio e mandar pra dentro, porque você está com fome, você vai alimentar e depois, talvez, você até dá uma cochilada no sofá né, dependendo do tempo. Mas assim, eu acho que essa troca vai te dá uma sensação de bem-estar, né?! Você, dependendo, uma hora de corridinha dá pra transpirar bem, ficar cansadinho, e depois chegar em casa e comer bem também. Então uma hora você dá pro meio, e depois você chega em casa e pega e retoma, eu acho.

Lucas: Então tem aquela parte energia também que você falou da pessoa, energia boa ou ruim, dependendo da pessoa. Então a pessoa que pratica exercício, ela vai se sentir melhor fisicamente e tudo o mais e ela também vai, vou falar assim, é uma pessoa mais feliz, uma pessoa mais, como eu poderia falar?

Ricardo: com um alto astral. 
A pergunta do pesquisador conduz os entrevistados a optarem por um dos caminhos da significação da energia: "a sua energia, eu acredito que diminui. A sua energia". Inicialmente, percebemos que Ricardo toma como base o discurso da ciência escolar para explicação da situação, posto que enuncia "trocas de energia com o meio", procurando, ao que parece, identificar fluxos de energia entre o sistema (corpo humano) e o meio: "você está transpirando né, tá perdendo em forma de calor, vai pegando seus nutrientes e queimando". No entanto, seu ponto de vista só tem seu pleno sentido realizado quando associado à sua concepção de "troca", a partir da compensação, ideia cotidiana, adquirida pelo bem-estar. Além disso, a energia aparece como algo quase substancial, presente nos nutrientes, que é liberada quando eles são "queimados". O discurso de Ricardo, um híbrido intencional, é o discurso da ciência escolar por meio da linguagem cotidiana: "então uma hora você dá pro meio, e depois você chega em casa e pega e retoma, eu acho".

Por sua vez, Lucas não questiona a afirmação de Ricardo, pelo contrário, parece assumi-la como sua. Ele vai abordar o problema por outro lado, isto é, pela via cotidiana: quando "a energia aumenta". Em seguida, Juliano, que participava do diálogo marginalmente, exibe certo incômodo em relação aos dois caminhos da significação da energia:

Juliano: A gente relaciona a prática, prática de exercício, eu tô perdendo energia, tô, de alguma forma... Se fizer essa relação...não sei.

Pesquisador: Mas ela é importante pra me sentir bem, é o que ele estava falando. Lucas estava falando. Então eu tenho um pequeno problema aí não? Tem uma energia que eu acumulo e outra que eu perco, não?

O pesquisador, prevendo que a fala de Juliano poderia criar condições para restrição dos significados em torno da energia, insiste na demarcação e polarização dos dois caminhos da significação do conceito. Faz nova provocação: "tem uma energia que eu acumulo e outra que eu perco, não?”.

Ricardo: É, mas essa questão da pessoa “estar bem”, acho que é muito pessoal né, tipo, às vezes pra eu estar bem é diferente do Lucas estar bem.

Pesquisador: Sim... [afirmativo com o sentido de prossiga]

Ricardo: É uma questão delicada. Às vezes, por exemplo, um exemplo clássico é minha irmã. Minha irmã pra ela estar bem ela tem que estar deitada e dormindo. Pra mim não dá, pra mim já não dá. Deitar e dormir é só de noite né, não dá. Então é diferente eu vou chamar minha irmã pra correr, vamos correr? Não, vai dar problema.

Lucas: Só acho que tem de pegar assim como um todo. Você teve um gasto 
energético, da prática de exercícios, você tem esse desgaste, mas você vai repor essa energia depois, acho que influi nos processos biológicos assim. Sei lá, liberação de hormônios, algo do tipo assim que a pessoa vá se sentir bem né e se sinta melhor que uma pessoa que, uma pessoa que desgastou, então teve essa prática de exercícios, mas não se alimentou corretamente, aquela pessoa às vezes vai ficar mais sonolenta então, baixo rendimento também...

Pesquisador: Fala Juliano, tá com sono aqui...

Juliano: É muito relativo, descansar e se sentir bem e tal, mas se você for pensar no conceito biológico e tal essas coisas, ah, hormônio, essas coisas, acho que a relação que eu faço amplamente é essa: a prática de exercícios vai, causa um desgaste energético que precisa ser reposto depois, por exemplo, um gasto de um cansaço, por exemplo, gastou energia, causou cansaço, fiquei cansado, preciso repor essa energia de alguma forma, então... Pode ser que era uma energia que tava armazenada... Tava armazenada e eu - voltando ao armazenamento...

Lucas: Eu sei lá, eu penso como se fosse, sei lá, um motor de um carro assim. Na hora que cê, cê tem que ter um engate né, êmbolo sei lá como chama, pra liberar energia pra você pôr aquelas outras peças pra funcionar. Eu acho que seria algo do tipo no corpo também, você precisa de algo, de uma prática de exercício pra acontecer alguns processos que são importantes.

Para Ricardo, a controvérsia da perda ou acúmulo de energia pode ser resolvida pela perspectiva subjetiva-individual que se opõe à objetiva-universal, ou seja, é admitida uma ambiguidade no âmbito pessoal na qual posso ganhar energia realizando ou não atividades físicas, entretanto "a sua energia, eu acredito que diminui. A sua "energia" (enuncia no início da interação), isto é, a energia objeto da ciência escolar, definitivamente, diminui.

Por outro lado, a resolução de Lucas é construída pela via da ciência escolar, apesar de dar sinais de que não se sinta totalmente confortável para explicação do ponto de vista biológico: "sei lá, liberação de hormônios, algo do tipo assim que a pessoa vá se sentir bem né $[\ldots]$ ". Assim, a realização de atividades físicas tem como consequência a perda de energia e a liberação de substâncias como os hormônios responsáveis pela sensação de bem-estar. Agora a troca é reinterpretada com a predominância do discurso da ciência escolar.

Após a instigação do pesquisador, Juliano soma-se à avaliação de Lucas ao oferecer uma explicação por meio de outro híbrido orgânico entre ciência escolar e visão materialista/substancialista de energia. Como no discurso científico, a energia aparece como grandeza que pode ser contabilizada em termos de ganhos e perdas (ou fluxos). Por outro lado, essa metáfora de algo que se gasta e se perde, podendo ser reposta e novamente guardada para uso posterior se alimenta de metáforas substancialistas. $\mathrm{O}$ discurso oscila, então entre o científico e o cotidiano. 
Por fim, Lucas demonstra por meio de sua analogia uma visão fortemente mecânica do funcionamento do organismo humano. Aqui, a analogia, o discurso mecânico, ou em outras palavras, a linguagem sobre mecanismos é pronunciada para dar sentido ao discurso da ciência escolar, restrita à física e reduzindo o biológico ao mecânico. É claro que o uso do recurso da analogia sempre carrega riscos para a compreensão da ciência escolar. Nesse caso, a energia pode converter-se numa espécie de substância lubrificante necessária ao funcionamento do organismo. Estamos, portanto, diante de um novo híbrido orgânico, não consciente e com fronteiras difusas.

\section{GRUPO FOCAL: PERDENDO ENERGIA A GENTE GANHA}

Este grupo foi constituído por dois participantes: $:^{19}$ uma estudante do $8^{\circ}$ (oitavo) período e outro do último período $\left(10^{\circ}\right)$ do curso de licenciatura em Ciências Biológicas. O tempo de duração total do grupo focal foi de aproximadamente 44 (quarenta e quatro) minutos, sendo que cerca de 32 (trinta e dois) minutos foram centrados nas questões do roteiro e o restante em conversas preparatórias e de finalização do grupo. Fizemos a opção por não transcrever as interações das duas primeiras questões em função do espaço limitado que dispomos e também porque já no primeiro grupo indicamos o modo como desenvolvemos os grupos focais.

Quando já eram decorridos pouco mais de 11 (onze) minutos de diálogo em grupo, foi introduzida a questão relativa à "energia e a prática de exercícios". Esta interação teve a duração de 3 (três) minutos e 12 (doze) segundos.

Pesquisador: Uma coisa pra gente pensar também, uma frase comum de escutar e ser dita também, que é a questão do exercício físico e energia. Muita gente fala assim, é muito comum você ouvir na mídia, pessoas, tá em todo lugar hoje, muito forte isso né: "a prática de exercícios físicos é importante para ter uma vida saudável”, né, ter uma vida melhor, uma vida... Então fazer exercício é importante né, como que vocês veem isso? Do ponto de vista da energia especialmente, né?

Fernando: Relacionando energia com isso? Xô ver... É porque, de certa forma, a gente ser saudável também, a mídia fala que a gente tem que gastar energia pra ser saudável né. Isso é outro ponto de vista, não sei...

Elen: Acho que isso volta àquele sentido amplo da energia de novo, sabe? Não só a energia do nosso corpo, que a gente produz ATP e quando tá fazendo movimento a gente tá gastando essa coisa toda. Mas num sentido que vai além sabe? Naquela questão da energia própria de cada um, porque daí, quando você começa a fazer exercício físico, aquilo ali começa a fazer bem pro seu corpo, pra sua mente, e então você fica mais disposto. A energia 
no sentido de estar mais disposto né. Pra poder fazer outras atividades e pra você conseguir correr, ou andar de bicicleta, ou fazer algumas coisas que às vezes, quando você não tem esse costume, pra você é mais difícil.

Outra vez, a relação entre energia e a prática de exercícios é introduzida pelo pesquisador com o propósito de criar condições favoráveis para a produção de enunciados híbridos. De início, Fernando tenta, mesmo que inseguro, descolar a afirmação para fora da ciência escolar: "isso é outro ponto de vista". Por sua vez, os enunciados de Elen exibem de forma bem nítida e segura os dois caminhos da significação da energia: de um lado, a energia gasta é a da ciência escolar ("ATP") e, de outro, "num sentido que vai além", cotidiano, "a energia de estar disposto".

Em seguida, o pesquisador tenta explorar melhor a demarcação de fronteiras dos usos do conceito de energia e uma possível contradição:

Pesquisador: Sim, mas aí talvez a gente tem uma, talvez não seja contradição, mas talvez uma coisa assim, é que pensar esse negócio de "exercício físico pra ter uma vida saudável", pensando energia, a gente podia pensar assim...mas, se eu faço exercício físico, eu ganho ou perco energia?

Elen: Depende. Você perde energia de ATP que você tá queimando, mas você ganha energia de vida, de ânimo, essas coisas.

Fernando: É, realmente, é meio contraditório mesmo né, porque, geralmente quem faz exercício, fala assim: nó, depois que eu malho, depois do exercício, eu me sinto tão bem, faço de tudo o resto do dia, o dia muito mais animado... aí se você for parar pra pensar, ela só perdeu energia né, então...Talvez, quando a gente pensa em humano acho que a gente pensa mais em um tipo... Energia assim, de movimento, essas coisas, mais sei lá tem energia espiritual também, não sei. Tem energia... Do ânimo, não sei, assim, você até converte uma coisa na outra, mas realmente é meio contraditório mesmo.

Elen: Ah, sei lá, quando você tá praticando exercício físico você tá queimando caloria, e aí você tá melhorando sua circulação sanguínea, sua respiração, você tá fazendo um monte de coisa boa pro seu corpo, acho que daí que vem esse bem-estar. Então, perdendo energia a gente ganha energia, sabe? Uma coisa meio contraditória, mas é interessante, quando se pensa nisso.

Elen parece bem consciente da delimitação de fronteiras e pronuncia uma síntese: "você perde energia de ATP que você tá queimando, mas você ganha energia de vida [...]". Essa é uma típica construção híbrida: percebemos dois tons, duas linguagens, dois universos semânticos e axiológicos. Fernando passa a reconhecer a existência de mais de uma energia em termos discursivos, mas isso parece perturbá-lo. Ele mobiliza a fala do outro, "nó, depois que eu malho, depois do exercício, eu me sinto tão bem”, para esclarecê-la pela ciência 
escolar (visão de mundo que parece ter maior privilégio para explicação da situação, "ela só perdeu energia né"). Entretanto, Fernando expõe um híbrido, a bem dizer, mais orgânico do que intencional, quando tem diante de si o "humano, que até converte uma coisa na outra".

A próxima explicação de Elen acerca da fala corriqueira "exercício físico pra ter uma vida saudável", dá-se através da linguagem da ciência escolar. Ela esclarece uma linguagem por meio da outra; conclui com um híbrido, nesse caso, intencional e se sente confortável com o reconhecimento das diferentes significações: "então, perdendo energia a gente ganha energia, sabe? Uma coisa meio contraditória, mas é interessante, quando se pensa nisso".

De modo geral, podemos dizer que os sujeitos e as interações dos grupos analisados, em maior ou menor medida, são referenciados e orbitam a linguagem da ciência escolar, ou seja, por mais que os sujeitos mobilizem distintas linguagens sociais ao longo das suas falas no decorrer dos grupos focais que não a da ciência escolar, esta última, por assim dizer, está presente no ar. Os sujeitos entrevistados possuem compromisso com o ensinar e aprender ciências (bolsistas do PIBID preocupados com seus educandos), que age como uma força (centrípeta) que os conduz para próximo do discurso da ciência escolar. É como se a vOz alheia da ciência escolar estivesse quase a todo tempo produzindo ecos do tipo: hora de voltar a falar sobre ciência; não posso aceitar certas visões de mundo; como vou explicar isso em sala de aula? Não tem cabimento; dentre outras.

Se de um lado, as questões introduzidas nas discussões dos grupos focais tendem a "descentralizar", isto é, favorecem a mobilização de sentidos da vida cotidiana, de outro lado, a força que centra ("puxa") a fala dos sujeitos em direção à ciência escolar, em termos culturais e discursivos, é decisiva para criação de condições favoráveis para que eles construam híbridos nos quais esteja presente pelo menos a linguagem social da ciência escolar. De outro modo, poderíamos dispor de híbridos intencionais ou orgânicos a partir de outras linguagens sociais - o que não era nosso objetivo, pois tínhamos por meta relacionar o processo de hibridização à aprendizagem de ciências.

Não há uma relação causal entre aquele que pronuncia e exibe enunciados híbridos e suas concepções híbridas ou ambíguas de mundo. $\mathrm{O}$ que queremos dizer, e as interações contribuíram para o desenvolvimento da nossa ideia, é que os sujeitos, ancorados nas suas visões de mundo, com o objetivo de construir explicações para determinadas situações, recorrem a enunciados híbridos, isto é, mobilizam o discurso do outro na linguagem do outro como modo de ser entendidos pelos seus interlocutores. 


\section{CONSIDERAÇÕES FINAIS}

Como síntese dos dados produzidos, percebemos quenos grupos focais dos professores em formação das áreas de física e biologia, o conceito de híbridos intencionais tornou-se uma importante alternativa interpretativa para a compreensão do conceito de energia (não da sua forma acabada, mas do processo, do seu desenvolvimento a partir dos sentidos que os sujeitos atribuem a ele em diferentes contextos), das interações verbais que envolvem o ensino e aprendizagem de ciências, como também do posicionamento ativo e responsivo dos licenciandos diante de e por meio do discurso científico.

Essa nova compreensão do híbrido no desenvolvimento de conceitos pode indicar para que os processos de ensino e aprendizagem que educadores e educandos em ciências estão implicados carregam mais da apropriação ativa e responsiva do discurso científico do que é corriqueiramente percebido. Isto é, ao assumir a perspectiva dos híbridos, o que antes poderia ser entendido como discurso misto, ambíguo, poluído, incoerente ou incompatível com a visão da ciência escolar, agora pode contar com nova possibilidade interpretativa que dá potência ao modo como o sujeito significa uma linguagem social a partir de outra: há mais sinais da aprendizagem do conceito científico para além do discurso predominantemente da ciência escolar.

Do ponto de vista do currículo podemos incorporar essa compreensão dos híbridos, notadamente dos intencionais, como forma de relativizar ${ }^{20}$ e dar nova potência aos resultados e metas do ensinar e aprender ciências. Igualmente, a discussão dos híbridos abre um debate importante no campo da pesquisa e da educação em ciências: o currículo de ciências deve também assumir os conhecimentos chamados de tradicionais, populares ou aqueles relacionados às vivências dos sujeitos? Nossa resposta é sim. Coerente com a abordagem vigostkiana para qual os conceitos evoluem como significados das palavras (VIGOSTKI, 2009), podemos afirmar que para o desenvolvimento do próprio conceito científico é condição necessária assumir o conceito cotidiano, especialmente quando ele é denominado pela mesma palavra; é condição para demarcação de fronteiras e a promoção do seu cruzamento; também é passo imprescindível para o diálogo intercultural. Isso não quer dizer que enxergamos o currículo de ciências, por assim dizer, de ponta cabeça ao defender o ensino dos conhecimentos não científico escolares. Em primeiro lugar, defendemos a meta do letramento científico escolar para todos, entendido como direito inegociável na sociedade 
contemporânea na qual vivemos. Mas em certa medida, especialmente tratando-se de conhecimentos relacionados a comunidades situadas ou aqueles que estruturam o modo de vida e atividades de determinado grupo social, podemos incorporá-los ao currículo em diferentes graus respondendo aos propósitos de reconhecimento, visibilidade, empoderamento ou até mesmo como meta de aprendizagem. Ao mesmo tempo, a escolha desses conteúdos não científicos escolares guardaria relação estreita com as possíveis pontes ou conexões com os conhecimentos já canônicos da ciência escolar. ${ }^{21}$

Segundo Bakhtin (2010), Dostoiévski soube auscultar relações dialógicas em toda parte $;^{22}$ percebeu sua época como um grande diálogo e captou nela não só vozes isoladas, mas antes a interação dialógica entre elas. Seu herói não pode ser visto somente como "um discurso sobre si mesmo e sobre seu ambiente imediato, mas também um discurso sobre o mundo: ele não é apenas um ser consciente, é um ideólogo" (BAKHTIN, 2010, p. 87) e, em decorrência, devemos levar em conta que a verdade do mundo é inseparável da verdade do indivíduo (o discurso sobre o mundo se funde com o discurso confessional sobre si mesmo).

A nosso modo, também auscultamos relações dialógicas no fenômeno híbrido relacionado ao conceito de energia; procuramos dar visibilidade e reconhecer as interações dialógicas que produziram enunciados híbridos, notadamente o intencional, no qual fica mais nítido os movimentos discursivos empregados por nossos sujeitos de esclarecimento de uma linguagem social por meio da outra; demos ênfase, por meio do processo de bivocalização, ao discurso sobre e a partir do cotidiano e da ciência escolar, isto é, dando relevo especial, em meio às relações dialógicas, à verdade de quem enuncia e à verdade do mundo.

Por fim, temos a convicção de que o híbrido, ou o conceito de construção híbrida, afasta-se da noção de amálgama (todo confuso e indiferenciado) e recoloca e dá potência positiva à (característica de) ambiguidade como componente discursiva do diálogo, do ensino e aprendizagem e, por que não, da vida social.

\section{REFERÊNCIAS}

ARAÚJO, A. O. de. O perfil conceitual de calor e sua utilização por comunidades situadas. Belo Horizonte: Faculdade de Educação/UFMG (Tese), 2014.

BAKHTIN, M. Questões de literatura e de estética: a teoria do romance. São Paulo: Hucitec, p. 71-163; p. 363-396, 1990. 
BAKHTIN, M. Problemas da poética de Dostoiévski. Rio de Janeiro: Forense Universitária, p. 3-51; 87-114; 207-233; 318-338, 2010.

BAKHTIN, M. Teoria do romance I: a estilística. São Paulo: Editora 34, 2015.

BARBOUR, R. Grupos focais. Porto Alegre: Artmed, 2009.

BEZERRA, P. Prefácio. In: BAKHTIN, M. Teoria do romance I: a estilística. São Paulo: Editora 34, 2015.

BHABHA, H. K. Signos tidos como milagres: questões de ambivalência e autoridade sob uma árvore nas proximidades de Dehli, em maio de 1817. In: BHABHA, H. K. O local da cultura. Belo Horizonte: Editora UFMG, 1998.

BRAGA, S. A. de M. O texto de biologia do livro didático de ciências. Belo Horizonte: Faculdade de Educação/UFMG (Tese), 2003.

BRANDIST, C. Mikhail Bakhtin e os primórdios da sociolinguística soviética. In: FARACO, C. A.; TEZZA, C.; CASTRO, G. Vinte ensaios sobre Mikhail Bakhtin. Rio de Janeiro: Vozes, 2006.

CANCLINI, N. G. Culturas Híbridas: Estratégias para entrar e sair da modernidade. São Paulo: Editora da Universidade de São Paulo, 2003.

CANCLINI, N. G. Diferentes, desiguais e desconectados. Rio de Janeiro: Editora UFRJ, 2009.

CARCAIOLI, G. F. \& ROSA, M. I. P. Culturas múltiplas, conhecimentos híbridos e um viveiro pedagógico. In: Encontro Nacional de Pesquisa em Educação em Ciências, IX, 2013. Anais. Águas de Lindóia (SP): ABRAPEC.

CREPALDE, R. dos S. Da energia pensada à energia vivida: um diálogo intercultural com as ciências. Belo Horizonte: Faculdade de Educação/UFMG (Dissertação), 2012.

CREPALDE, R. dos S. \& AGUIAR JR., O. G. A formação de conceitos como ascensão do abstrato ao concreto: da energia pensada à energia vivida. Investigações em Ensino de Ciências, v. 18(2), p. 299-325, 2013.

CREPALDE, R. dos S. \& AGUIAR JR., O. G. A construção híbrida intencional da palavra energia no ensino-aprendizagem de ciências. In: $37^{a}$ Reunião Nacional da ANPEd, 2015. Anais. Florianópolis (SC): ANPEd.

FARACO, C. A.. Linguagem \& diálogo: as ideias linguísticas do círculo de Bakhtin. São Paulo: Parábola Editorial, 2009.

FLORES, V.do N.; BARBISAN, L. B.; FINATTO, M. J. B.; TEIXEIRA, M. (org.). Dicionário de Linguística da Enunciação. São Paulo: Contexto, 2009.

GATTI, B. A.. Grupo focal na pesquisa em ciências sociais e humanas. Brasília: Liber Livro Editora, 2012.

LOPES, A. R. C. Conhecimento escolar: ciência e cotidiano. Rio de Janeiro: Eduerj, 1999.

MATOS, M. do C. de \& PAIVA, E. V. de. Hibridismo e currículo: ambivalências e possibilidades. Currículo sem Fronteiras, v.7, n.2, p.185-201, Jul/Dez 2007.

MCLAREN, P. Multiculturalismo crítico. São Paulo: Cortez, 1997.

MORSON, G. S. \& EMERSON, C. Mikhail Bakhtin: criação de uma prosaística. São Paulo: Edusp, 2008. 
RENFREW, A. Mikhail Bakhtin (Routledge Critical Thinkers). New York: Routledge (edição Kindle) , cap. 5, 6 e 7, 2015.

TEZZA, C. Entre a prosa e a poesia: Bakhtin e o formalismo russo (ebook). Curitiba: Tovo Textos, 2013.

TURA, M. de L. R. A recontextualização por hibridismo na prática pedagógica da disciplina ciências. Currículo sem Fronteiras, v.9, n.2, p.133-148, Jul/Dez 2009.

VIGOTSKI, L. S. A construção do pensamento e da linguagem. Trad. Paulo Bezerra. São Paulo: Martins Fontes, 2009.

\section{NOTAS DE FIM}

${ }^{1}$ Agradecimentos à CAPES e ao CNPq (projeto 309361/2016-8).

${ }^{2}$ Canclini (2003) estudou o que chamou de culturas híbridas latino americanas que teriam sua gênese na sedimentação, justaposição e entrecruzamento de tradições indígenas, do hispanismo colonial católico e das ações políticas educativas e comunicacionais modernas.

${ }^{3}$ Para Bhabha (1998), o hibridismo é resultado do efeito discriminatório do discurso colonial entre a cultura "mãe" e as culturas "alienígenas". É produzida via estratégia de recusa, onde o traço que é recusado não é reprimido, mas repetido como algo diferente (o sentido original é deslocado, sofre uma mutação).

${ }^{4}$ Não é a composição formal que define o romance (a diferença de romance, novela e conto, por exemplo), mas sim o modo como ele se relaciona com a vida da linguagem (TEZZA, 2013). Segundo Brandist, "os ensaios de Mikhail Bakhtin sobre o romance na década de 1930 constituem talvez sua contribuição mais original, influente e valiosa para o estudo das línguas e literaturas europeias" (BRANDIST, 2006, p. 67).

${ }^{5}$ Incluem nessa obra os ensaios "Discurso no romance", escrito em 1934-35; e, "Da préhistória do discurso romanesco", de 1940. Recentemente, foi publicada nova tradução do texto "Discurso no romance", a partir do texto integral, diretamente da língua Russa, realizada por Paulo Bezerra que também incorporamos ao nosso trabalho: Teoria do romance I: a estilística. Ver referências, Bakhtin (2015).

${ }^{6}$ Segundo Paulo Bezerra, tradutor de Bakhtin (2015), o termo russo é raznorétchie (raznii diferente, diverso + riétchie - discurso, fala, linguagem).

${ }^{7}$ Dialetos relacionados à função social (profissão, classe, etc.) e não no sentido estrito linguístico.

8 "Da pré-história do discurso romanesco", conferência com a temática do "discurso no romance" realizada em 1940 que só mais tarde, entre 1965-1967, seria publicada.

${ }^{9}$ Nesse texto Bakhtin alterna o uso das expressões híbrido estilístico e construção híbrida literariamente organizada.

${ }^{10} \mathrm{Ou}$ "duplo tom" segundo a tradução da edição da HUCITEC, Bakhtin (1990).

${ }^{11}$ No texto "Da pré-história do discurso romanesco" usa a expressão híbrido estilístico intencional e híbrido dialogizado premeditado para caracterizar o híbrido intencional da paródia (BAKHTIN, 1990).

${ }^{12}$ Os falantes não se preocupam, de modo mais ou menos automático, se a palavra do outro pode ser percebida ou detectada. Do contrário, teríamos uma bivocalização (MORSON \& EMERSON, 2008). 
${ }^{13}$ Como exemplo, médicos podem discutir um caso clínico pressupondo que ele só possa ser dito na linguagem "médica". A possibilidade do heterodiscurso não é levada em conta.

${ }^{14}$ A referência ao termo "intencional" pode causar certa confusão. Num sentido comum, poderíamos dizer que todos os híbridos poderiam ser mais ou menos intencionais; que um híbrido orgânico pode ser pronunciado de forma intencional; ou que um híbrido intencional pode ser dito de forma que fuja ao controle de quem enuncia. No entanto, é fundamental destacar que Bakhtin emprega "intencional” para referir-se a um procedimento estilístico, projeto ou tarefa do discurso de "mobilização" de duas ou mais linguagens sociais em torno de um enunciado. Portanto, como veremos mais adiante, o híbrido intencional é aquele que é formado pela bivocalização de discursos.

${ }^{15}$ Os nomes dos sujeitos que aqui apresentamos neste trabalho são fictícios a fim de preservar suas identidades.

${ }^{16}$ Em algumas pesquisas que utilizam a metodologia dos grupos focais é possível encontrar a figura do moderador, indivíduo que é instruído e preparado com antecedência pelo pesquisador, para fazer o papel de mediador do grupo.

${ }^{17}$ Essas questões em torno do conceito energia, tanto na esfera cotidiana como na científica escolar, vêm sendo construídas e reelaboradas desde a dissertação de mestrado: Da energia pensada à energia vivida: um diálogo intercultural com as ciências (ver CREPALDE, 2012).

${ }^{18}$ As conversas de finalização do grupo, ao se estenderem para além do que pensávamos no planejamento inicial, deram conteúdo novo ao grupo focal como um todo que foi constituirse em um espaço, mesmo que breve, de ensino e aprendizagem de ciências.

${ }^{19}$ Outros dois participantes que estavam previamente confirmados não compareceram.

${ }^{20}$ Relativizar não quer dizer assumir um relativismo extremo que prega o abandono de qualquer meta ou até mesmo a necessidade do currículo. Empregamos relativizar como movimento ou procedimento de descarregar das metas e resultados da educação em ciências a presença unívoca do discurso (citado) predominantemente científico (escolar) e dar nova ênfase e reconhecer diferentes modos de pensar e dizer de outras esferas de significação inseparáveis das vidas dos educandos.

${ }^{21}$ Por exemplo, discutir nas aulas de ciências a influência da Lua no modo de crescimento de cabelos ou no nascimento de bebês pode ficar restrita ao reconhecimento respeitoso de um modo de pensar e dizer de determinado grupo social. Mas o modo como uma comunidade utiliza o ciclo lunar para organizar a plantação, a colheita, os tempos de trabalho e de lazer pode oferecer ao currículo de ciências várias pontes e conexões com o conhecimento canônico: marés (força gravitacional), fotossíntese, nicho ecológico, ecossistema, dentre outros.

${ }^{22} \mathrm{O}$ próprio Bakhtin e os autores do chamado "Círculo" souberam auscultar relações dialógicas em toda parte.

Submetido: $14 / 08 / 2017$

Aprovado: 19/03/2018

Contato:

Av. Randolfo Borges Júnior, 1400 - Univerdecidade Uberaba $|\mathrm{MG}|$ Brasil

CEP 38.064-200 